\title{
Combined Influence of Ferrofluid and Longitudinal Roughness on Porous Parallel Stepped Plates with Couple Stress
}

\author{
Yogini. D. Vashi ${ }^{1}$, Rakesh. M. Patel ${ }^{2}$, Gunamani. M. Deheri ${ }^{3}$ \\ ${ }^{1}$ Department of Applied Sciences and Humanity, Alpha College of Engineering and technology, Gujarat \\ Technological University, Gujarat, India \\ ${ }^{2}$ Department of Mathematics, Gujarat Arts and Science College, Ahmedabad, Gujarat-380006, India \\ ${ }^{3}$ Department of Mathematics, Sardar Patel University, Vallabh vidyanagar, Gujarat--388120, India \\ Email yogini.vashi@gmail.com ${ }^{1}$,rmpatel12711@gmail.com², gm.deheri@ rediffmail.com ${ }^{3}$
}

\begin{abstract}
This article discusses the theoretical study of a ferrofluid based squeeze film between longitudinally rough stepped plates with couple stress effect. For the roughness effect Christensen and Tonder stochastic model has been employed. While the magnetic fluid flow is governed by the model of Neuringer - Roseinweig. On the basis of Stokes microcontinuum model for couple stress fluid the Reynolds' type equation is established. The solution of this equation with suitable boundary conditions results in the computation of load bearing capacity. The graphical and tabular representation asserts that joint influence of magnetization and couple stress is to rise the load bearing capacity irrespective of the situation. It is noticed that the couple stress effect alone fails to be sufficient in overcoming the adverse influence of the roughness and porosity. However, it is the ferrofluid lubrication which adds to the optimistic effect of couple stress there by countering the above said adverse effect. This investigation underlines that one needs to consider the position of step carefully for design point of view. It is motivating to note that the standard deviation related with roughness tends to rise the load bearing capacity which, is in contrast to the situation of transverse roughness.
\end{abstract}

Index Terms-Load bearing capacity, ferrofluid, longitudinal roughness, parallel stepped plates.

\section{INTRODUCTION}

Now a days the flow of non Newtonian fluids have been extensively used in many industries and current technology which, directed numerous researcher to attempt various flow problems associated with nonNewtonian fluids. One of the most important theory of couple stress fluid given by Stokes [1]. To overcome the necessity of recent machine system working severe situations, the enlarged use of different types of non Newtonian fluid as lubricant has been highlighted. The use of additives in the lubricant reduce the compassion of lubricants to changes in shear rate and which supports restored load bearing capacity and response time. The micro polar theory for porous parallel stepped plates analysed by [2] concluded that impact of non Newtonian micro polar fluid initiate to improve the load bearing capacity.

Several studies have been made on the hydrodynamic squeeze film lubrication with couple stress fluid and the studies discovered that the couple stress fluid boosted the load carrying capacity and response time as related to the Newtonian case. [3], [4], [5], [6], [7], [8].

Lubrication play a significant role in bearing as it reduce the friction in the bearing. Now a days ferrofluid as lubricant is used in various engineering applications like material science, heat transfer, dynamic sealing, damping etc. It is a liquid that becomes strongly magnetized in the existence of magnetic field. Various investigator has used ferrofluid as lubricant for their study. Shah [9] studied the influence of ferrofluid in step bearing by two steps. His study revealed that the overall performance of the bearing upgraded by ferrofluid. In the current years surface roughness and its effects on machine design are important features which have been widely studied. Some approaches have been proposed to study the consequence of surface roughness on the bearing performance. Due to the random structure of the surface roughness, a stochastic model for the study of hydrodynamic lubrication has been developed by Christensen and Tonder [10,11,12] and this model has been used by many researchers for example Andharia and Deheri [13] analysed the influence of longitudinal roughness with ferrofluid based squeeze film lubrication in truncated conical plates. Study concluded that pressure, load carrying capacity and response time enhanced due to ferrofluid lubrication. Shimpi and Deheri [14] extended the work of Andharia and Deheri [12] by considering the deformation effect with slip velocity. Patel and Deheri [15] investigated the ferrofluid lubrication on longitudinally rough conical plates with slip velocity. This investigation proposed that negative influence of slip and roughness can be compensated with positive 


\section{Available online at www.ijrat.org}

influence of magnetization and standard deviation. Patel et al. [16] extended the above work with considering deformation effect and different form of magnitude of magnetic field. Ramesh et al. [17] studied numerically the rough porous rectangular plates with magnetic field. It was observed from their study Pressure and load bearing capacity are found to be enhanced as increasing the values of Hartmann number and roughness parameter. Vashi et al. [19] investigated the combined influence of surface roughness and ferrofluid lubrication on parallel stepped plates in the existences of couple stress fluid. Their study discovered that load bearing capacity is enhanced by use of ferrofluid as a lubricant.

\section{ANALYSIS}

The Figure 1 displays the physical structure of the bearing system. The upper plate is moving towards to the fixed lower porous plate with normal velocity $v$ The film region is filled by incompressible ferrofluid based couple stress fluid.

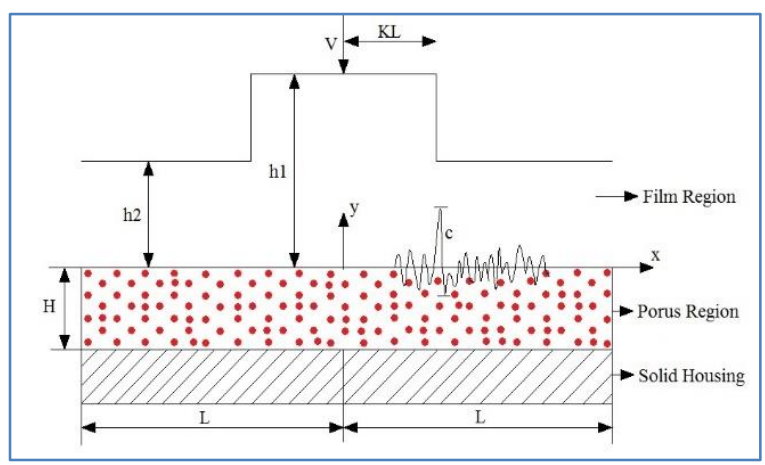

Fig.1. Configuration of bearing geometry

With the assumptions of hydrodynamic lubrication, the generalized Reynolds' type equation for pressure distribution is turns out to be [Biradar (2012)].

$\frac{d p_{i}}{d x}=\frac{-12 \mu V x}{G_{i}\left(h_{i}, l\right)}$

$G_{i}\left(h_{i}, l\right)=h_{i}{ }^{3}+12 \varphi H-12 l^{2} h_{i}+24 l^{3} \tanh \left(\frac{h_{i}}{2 l}\right)$

for smooth bearing.

Now in the view of stochastic averaging techniques of Christensen and Tonder (19969a, 1969b, 1970) for longitudinal roughness with nonzero mean one gets the Reynolds' type equation leading the fluid film pressure is $\frac{d p_{i}}{d x}=\frac{-12 \mu V x}{g_{i}\left(h_{i}, l\right)}$

Where

$$
\begin{aligned}
& g_{i}\left(h_{i}, l\right)=\frac{1}{E\left(h_{i}^{-3}\right)}+12 \varphi H-12 l^{2} \frac{1}{E\left(h_{i}^{-1}\right)^{+}} \\
& 24 l^{3} \tanh \left(\frac{\frac{1}{E\left(h_{i}^{-1}\right)}}{2 l}\right) \\
& g_{i}\left(h_{i}, l\right)=\frac{1}{m\left(h_{i}, \alpha, \sigma, \varepsilon\right)}+12 \varphi H- \\
& 12 l^{2} \frac{1}{n\left(h_{i}, \alpha, \sigma, \varepsilon\right)}+24 l^{3} \tanh \left(\frac{\frac{1}{n\left(h_{i}, \alpha, \sigma, \varepsilon\right)}}{2 l}\right) \\
& m\left(h_{i}, \alpha, \sigma, \varepsilon\right)=h_{i}^{-3}\left(\begin{array}{l}
1-3 \alpha h_{i}^{-1}+6 h_{i}^{-2}\left(\sigma^{2}+\alpha^{2}\right)- \\
10 h_{i}^{-3}\left(3 \sigma^{2} \alpha+\alpha^{3}+\varepsilon\right)
\end{array}\right) \\
& n\left(h_{i}, \alpha, \sigma, \varepsilon\right)= \\
& h_{i}{ }^{-1}\left(1-\alpha h_{i}{ }^{-1}+h_{i}{ }^{-2}\left(\sigma^{2}+\alpha^{2}\right)-h_{i}{ }^{-3}\left(3 \sigma^{2}+\alpha^{3}+\varepsilon\right)\right)
\end{aligned}
$$

Where,

$h_{i}=h_{1}$ for $0 \leq x \leq K L$ and

$h_{i}=h_{2}$ for $K L \leq x \leq L$

Resorting to the magnetic fluid flow model of Neuringer Rosenweig (1964) the above Eq. (2) transfer to

$$
\frac{d}{d x}\left[p_{i}-0.5 \mu_{0} \bar{\mu} H^{2}\right]=\frac{-12 \mu V x}{g_{i}\left(h_{i}, l\right)}
$$

where

$$
H^{2}=A(L-x)(x-K L)
$$

where in $\mathrm{A}$ is a suitable constant dependent on the material to produce a field of desired magnetic strength.

The pressure boundary conditions are

$$
p_{1}=p_{2} \text { at } x=K L \text { and } p_{2}=0 \text { at } x=L
$$

The solution of Eq. (3) under the above boundary condition is given respectively, by 


\section{Available online at www.ijrat.org}

$$
\begin{aligned}
p_{1}= & \frac{6 \mu V}{g_{1}\left(h_{1}, l\right)}\left(K^{2} L^{2}-x^{2}\right)+ \\
& \frac{6 \mu V}{g_{2}\left(h_{2}, l\right)}\left(L^{2}-K^{2} L^{2}\right)+0.5 \mu_{0} \bar{\mu} H^{2} \\
p_{2}= & \frac{6 \mu V}{g_{2}\left(h_{2}, l\right)}\left(L^{2}-x^{2}\right)+0.5 \mu_{0} \bar{\mu} H^{2}
\end{aligned}
$$

\section{Where}

$$
\begin{aligned}
& g_{1}\left(h_{1}, l\right)=\frac{1}{m\left(h_{1}, \alpha, \sigma, \varepsilon\right)}+12 \varphi H- \\
& 12 l^{2} \frac{1}{n\left(h_{1}, \alpha, \sigma, \varepsilon\right)}+24 l^{3} \tanh \left(\frac{\frac{1}{n\left(h_{1}, \alpha, \sigma, \varepsilon\right)}}{2 l}\right)
\end{aligned}
$$

$$
\begin{aligned}
& G_{1}=\frac{h_{2}{ }^{3}}{g_{1}\left(h_{1}, l\right)}=\frac{1}{M\left(H^{*}, \alpha^{*}, \sigma^{*}, \varepsilon^{*}\right)}+ \\
& 12 \psi-\frac{3 l^{*^{2}}}{N\left(H^{*}, \alpha^{*}, \sigma^{*}, \varepsilon^{*}\right)}+
\end{aligned}
$$

$$
3 l^{*^{3}} \tanh \left(\frac{1}{N\left(H^{*}, \alpha^{*}, \sigma^{*}, \varepsilon^{*}\right) l^{*}}\right)
$$

$G_{2}=\frac{h_{2}{ }^{3}}{g_{2}\left(h_{2}, l\right)}=$

$$
\begin{gathered}
g_{2}\left(h_{2}, l\right)=\frac{1}{m\left(h_{2}, \alpha, \sigma, \varepsilon\right)}+12 \varphi H-12 l^{2} \frac{1}{n\left(h_{2}, \alpha, \sigma, \varepsilon\right)}+ \\
24 l^{3} \tanh \left(\frac{\frac{1}{n\left(h_{2}, \alpha, \sigma, \varepsilon\right)}}{2 l}\right)
\end{gathered}
$$

The expression of load capacity is achieved as

$$
w=2 b \int_{0}^{K L} p_{1} d x+2 b \int_{K L}^{L} p_{2} d x
$$

which takes the form

$$
\begin{gathered}
w=\frac{b L^{3} A \mu_{O} \bar{\mu}}{6}(1-3 K)+ \\
8 b \mu V L^{3}\left[\frac{K^{3}}{g_{1}\left(h_{1}, l\right)}+\frac{\left(1-K^{3}\right)}{g_{2}\left(h_{2}, l\right)}\right]
\end{gathered}
$$

The expression for dimensionless load capacity can be described as

$$
\bar{w}=\frac{w h_{2}{ }^{3}}{8 \mu V b L^{3}}=\frac{\mu^{*}(3 K-1)}{6}+\left[\frac{K^{3}}{G_{1}}+\frac{\left(1-K^{3}\right)}{G_{2}}\right]
$$

where
$\frac{1}{M\left(\alpha^{*}, \sigma^{*}, \varepsilon^{*}\right)}+12 \psi-\frac{3 l^{*^{2}}}{N\left(\alpha^{*}, \sigma^{*}, \varepsilon^{*}\right)}+$
$3 l^{*^{3}} \tanh \left(\frac{1}{N\left(\alpha^{*}, \sigma^{*}, \varepsilon^{*}\right) l^{*}}\right)$

Where

$$
\begin{aligned}
& M\left(H^{*}, \alpha^{*}, \sigma^{*}, \varepsilon^{*}\right)= \\
& H^{*^{-3}}\left(\begin{array}{l}
1-3 \alpha^{*} H^{*^{-1}}+6 H^{*^{-2}}\left(\sigma^{*^{2}}+\alpha^{*^{2}}\right)- \\
10 H^{*^{-3}}\left(3 \sigma^{*^{2}} \alpha^{*}+\alpha^{*^{3}}+\varepsilon^{*}\right)
\end{array}\right) \\
& N\left(H^{*}, \alpha^{*}, \sigma^{*}, \varepsilon^{*}\right)= \\
& H^{*^{-1}}\left(\begin{array}{l}
\left.1-\alpha^{*} H^{*^{-1}}+H^{*^{-2}}\left(\sigma^{*^{2}}+\alpha^{*^{2}}\right)-\right) \\
H^{*^{-3}}\left(3 \sigma^{*^{2}}+\alpha^{*^{3}}+\varepsilon^{*}\right) \\
M\left(\alpha^{*}, \sigma^{*}, \varepsilon^{*}\right)= \\
\left(1-3 \alpha^{*}+6\left(\sigma^{*^{2}}+\alpha^{*^{2}}\right)-\right. \\
10\left(3 \sigma^{*^{2}} \alpha^{*}+\alpha^{*^{3}}+\varepsilon^{*}\right) \\
N\left(\alpha^{*}, \sigma^{*}, \varepsilon^{*}\right)= \\
\left(1-\alpha^{*}+\left(\sigma^{*^{2}}+\alpha^{*^{2}}\right)-\left(3 \sigma^{*^{2}} \alpha^{*}+\alpha^{*^{3}}+\varepsilon^{*}\right)\right.
\end{array}\right)
\end{aligned}
$$

\section{RESULT AND DISCUSSION}

This study predicts the performance of a ferrofluid squeeze film between longitudinally rough stepped plates considering couple stress effect. Eq.14 represents the dimension less load carrying capacity. Load carrying capacity is enhanced by using ferrofluid as a lubricant as compared to the couple stress fluid based bearing system. Also, comparison is 


\section{Available online at www.ijrat.org}

made between ferrofluid based bearing system and couple stress fluid based bearing system. Figure 2 to 7display the distribution of $\bar{w}$ with regards to $\mu^{*}$ for various values of $\sigma^{*}, \alpha^{*}, \varepsilon^{*}, \psi$.It is perceived that the $\bar{w}$ rises as the value of $\mu^{*}$ increases. Figure 7 describes that influence of $\mu^{*}$ can be found noticeable for different values of $l^{*}$.

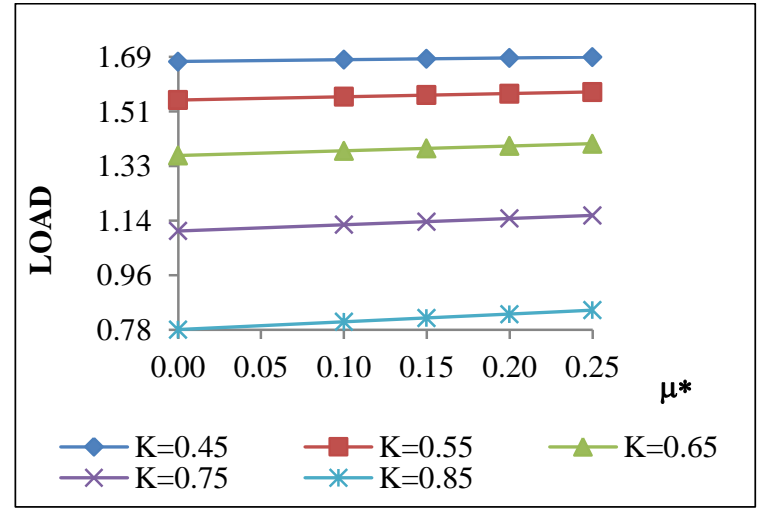

Fig. 2. Profile of $\bar{w}$ for the combination of $\mu^{*}$ and $K$

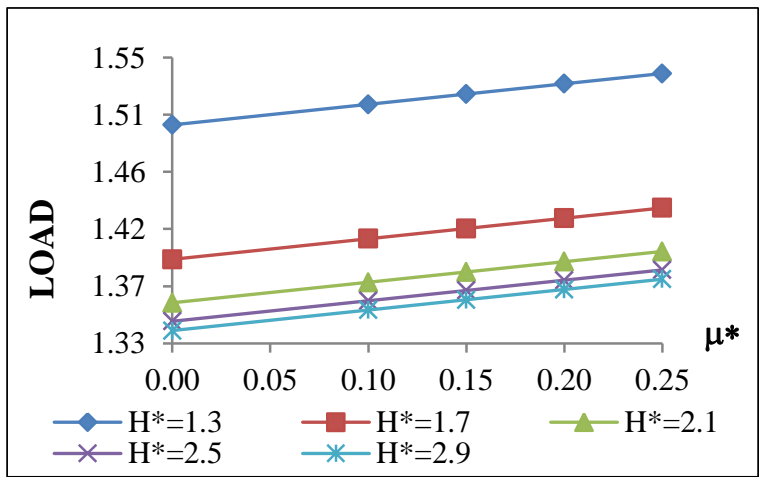

Fig. 3. profile of $\bar{w}$ with regards to $\mu^{*}$ and $H^{*}$

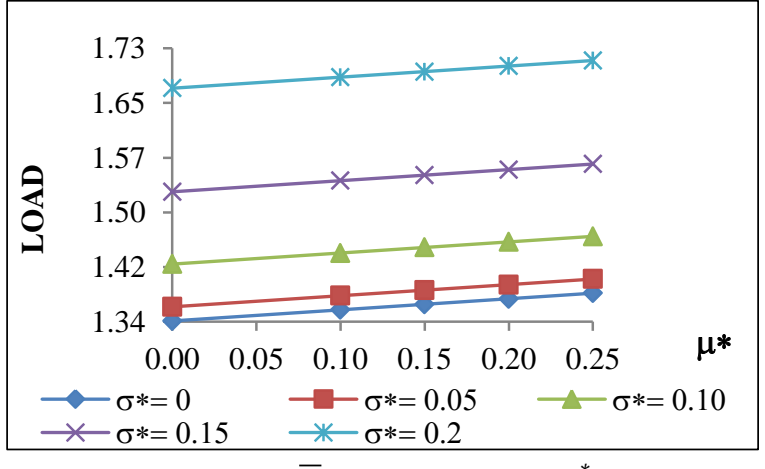

Fig. 4. Profile of $\bar{w}$ with reference to $\mu^{*}$ and $\sigma^{*}$

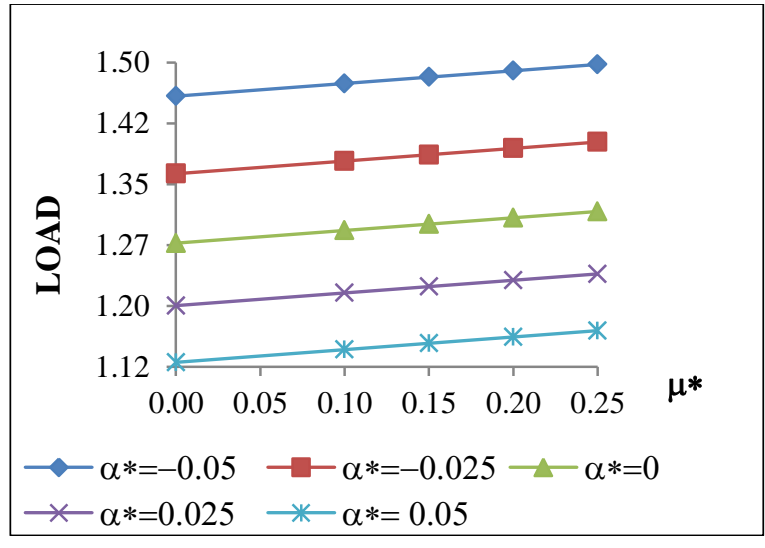

Fig. 5. Change in $\bar{w}$ concerned with $\mu^{*}$ and $\alpha^{*}$.

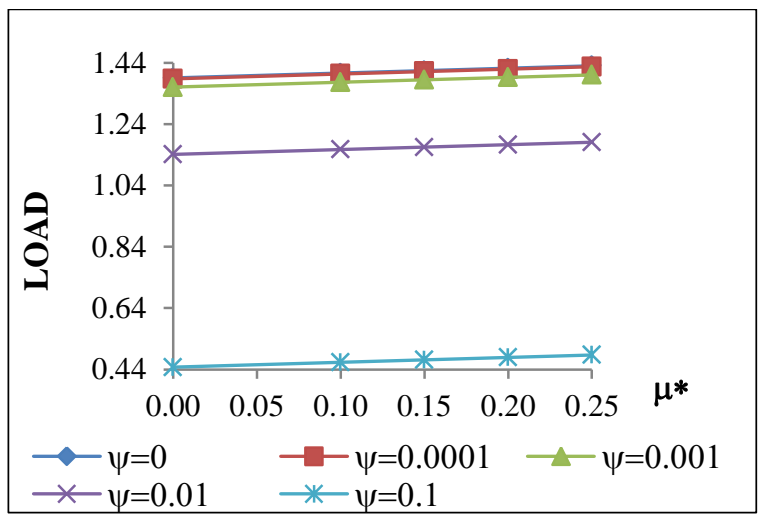

Fig. 6. Variation of $\bar{w}$ concerned with $\mu^{*}$ and $\psi$

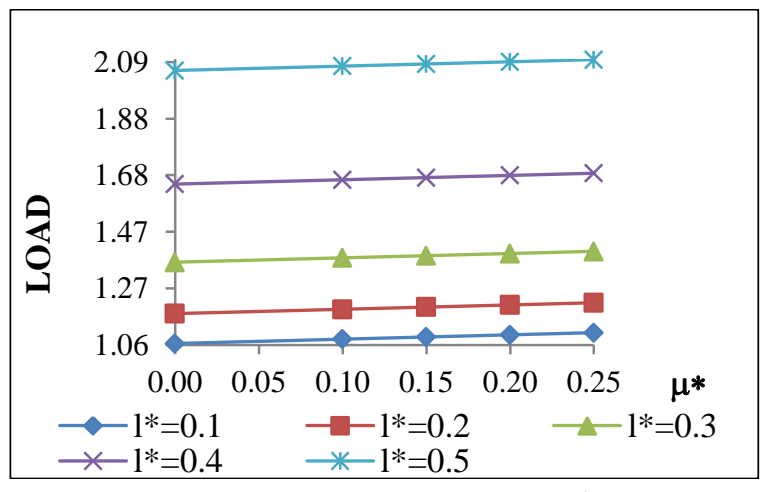

Fig. 7 Distribution of $\bar{w}$ reference to $\mu^{*}$ and $l^{*}$

The influence of step location on $\bar{w}$ with regards to $H^{*}, \sigma^{*}, \varepsilon^{*}, \psi, I^{*}$ is presented in Fig 8-12.

As the value of $K$ increases the load is decreases. 
Available online at www.ijrat.org

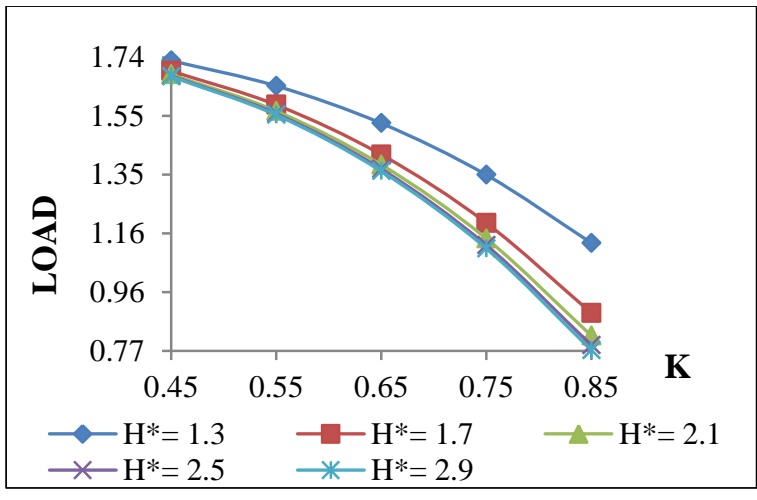

Fig 8. Profile of $\bar{w}$ reference to $K$ and $H^{*}$

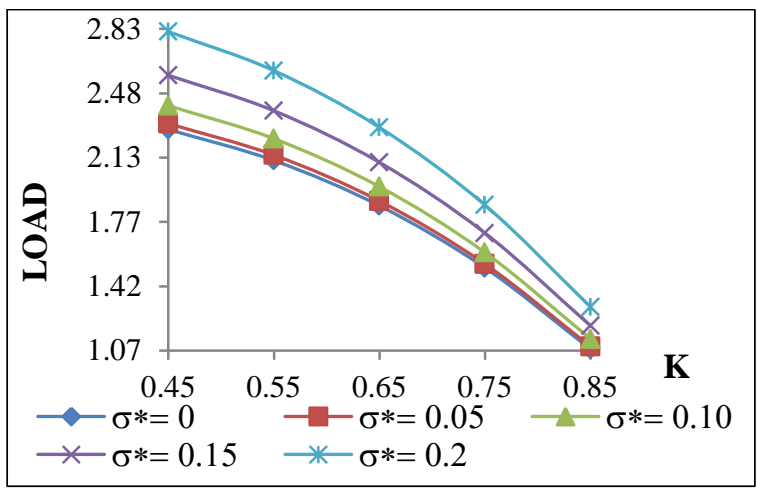

Fig 9. Trends of $\bar{w}$ reference to $K$ and $\sigma^{*}$

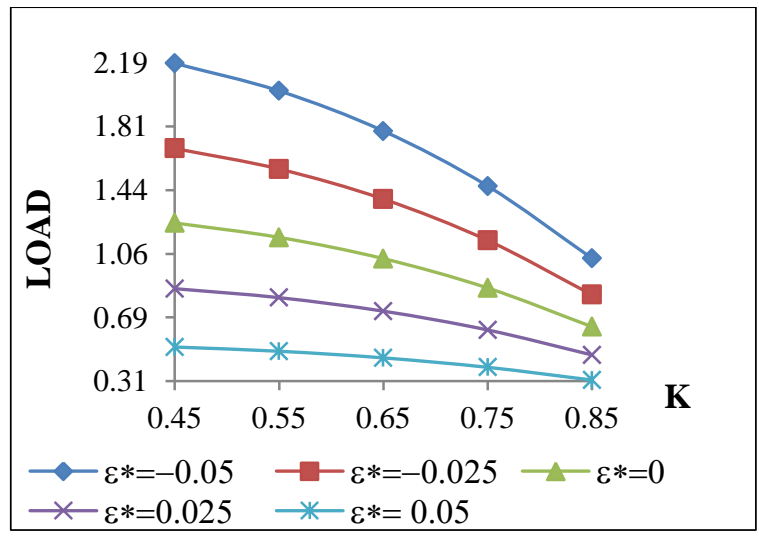

Fig 10. Profile of $\bar{w}$ reference to $K$ and $\varepsilon^{*}$

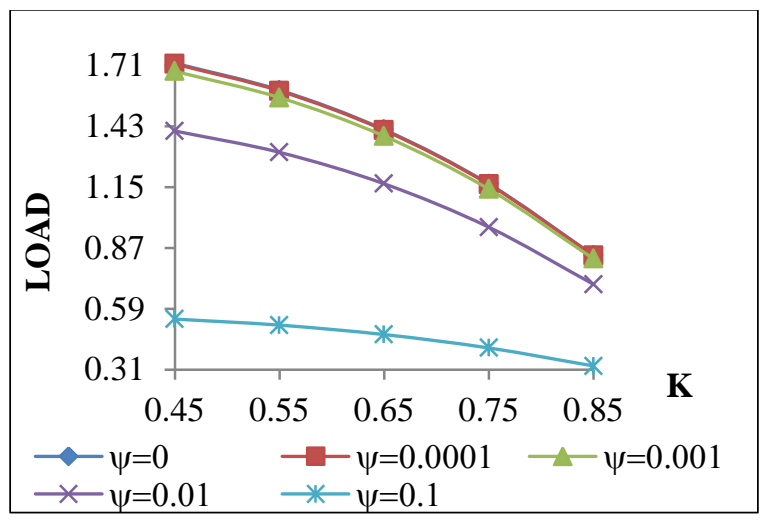

Fig 11. Trends of $\bar{w}$ reference to $K$ and $\psi$

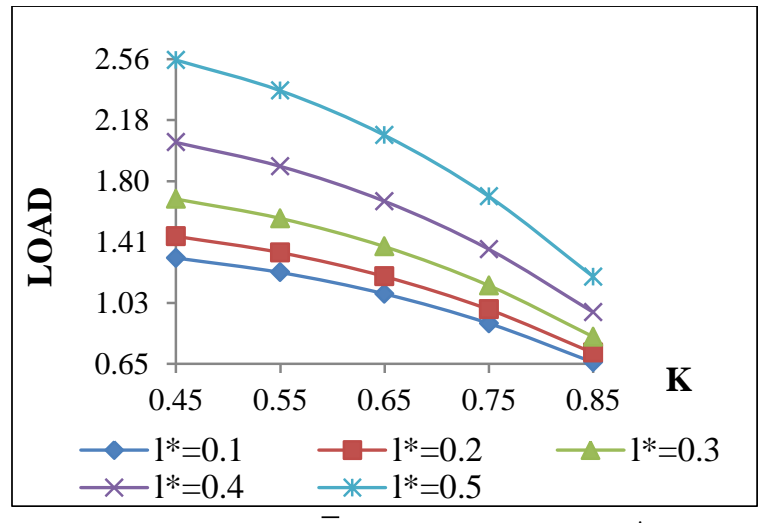

Fig 12. Trends of $\bar{w}$ reference to $K$ and $l^{*}$

The influence of $H^{*}$ on $\bar{w}$ with regards to $\sigma^{*}, \varepsilon^{*}, \psi, l^{*}$ is represented in Fig 13-16. Influence $H^{*}$ on load bearing capacity can be seen adversely. From Fig 16 it is perceived that the load drop is nominal with regards $l^{*}$. From Fig 15 remarked that the initial influence of $\psi$ on $\bar{w}$ is insignificant up to $\psi=0.001$

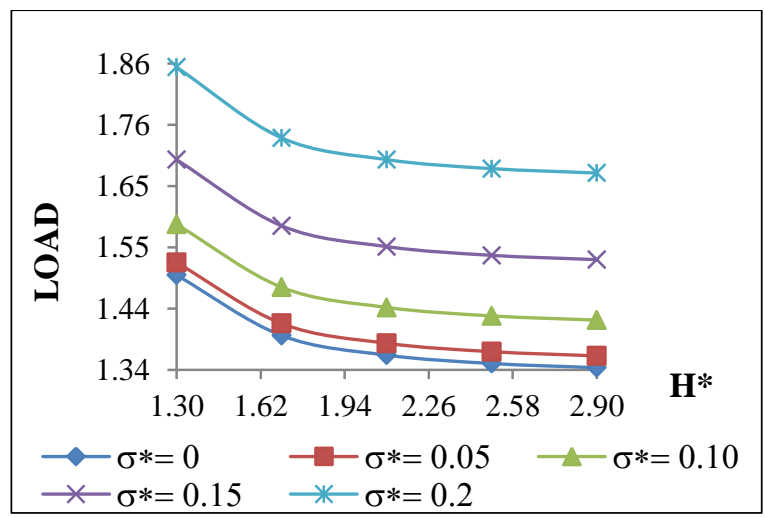

Fig 13. Trends of $\bar{w}$ reference to $H^{*}$ and $l^{*}$

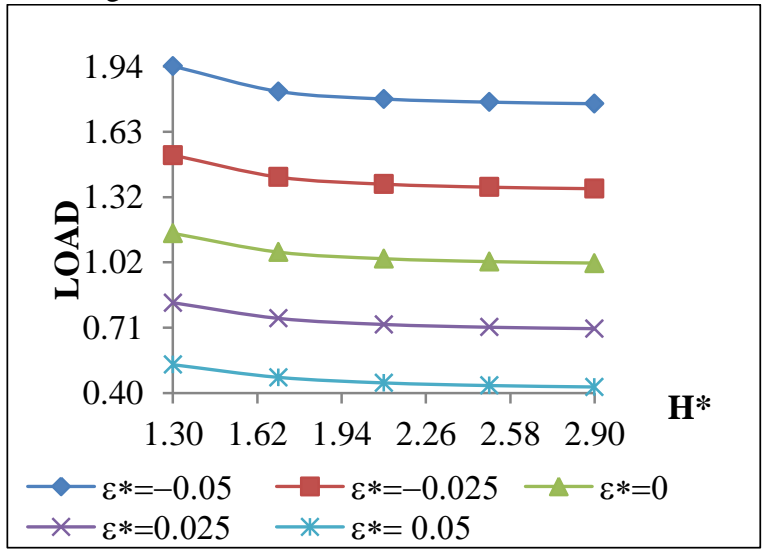

Fig 14. Trends of $\bar{w}$ reference to $H^{*}$ and $\varepsilon^{*}$ 


\section{Available online at www.ijrat.org}

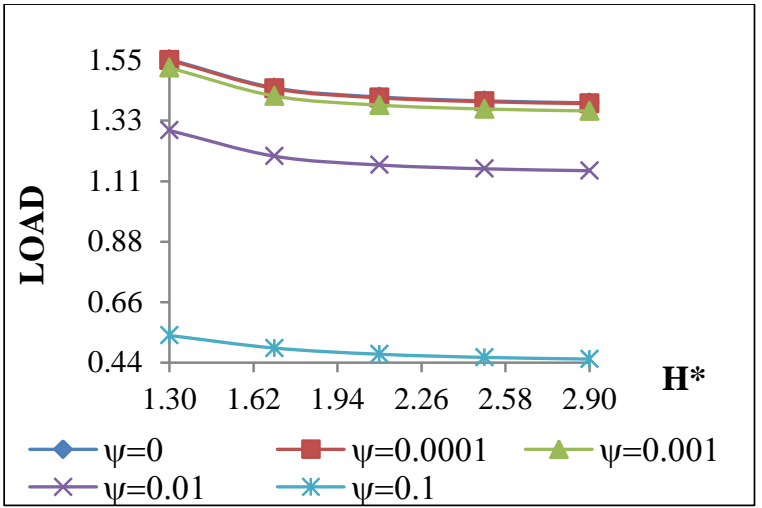

Fig 15. Trends of $\bar{w}$ reference to $H^{*}$ and $\psi$

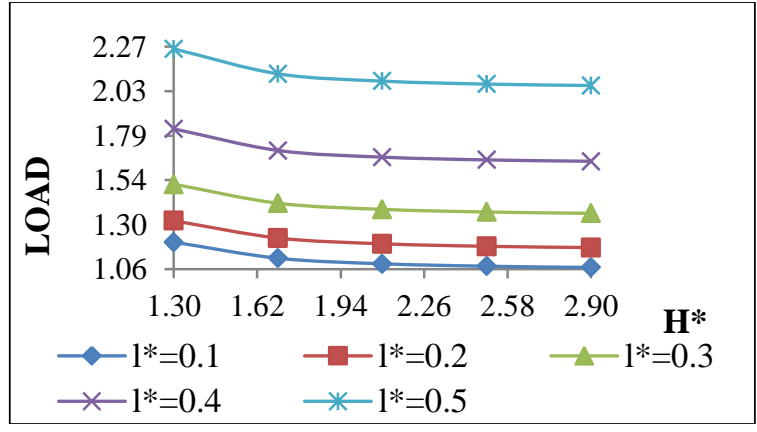

Fig 16. Trends of $\bar{w}$ reference to $H^{*}$ and $l^{*}$

Fig $17-19$ represents the impact $\sigma^{*}$ on load bearing capacity for various values of $\alpha^{*}, \psi, l^{*}$.Increasing the value of $\sigma^{*}$ the value of $\bar{w}$ is also rises.

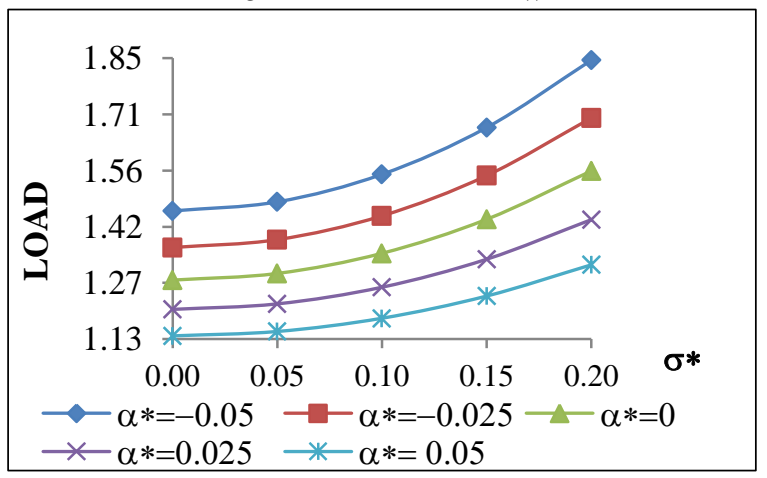

Fig 17. Distribution of $\bar{w}$ reference to $\sigma^{*}$ and $\alpha^{*}$

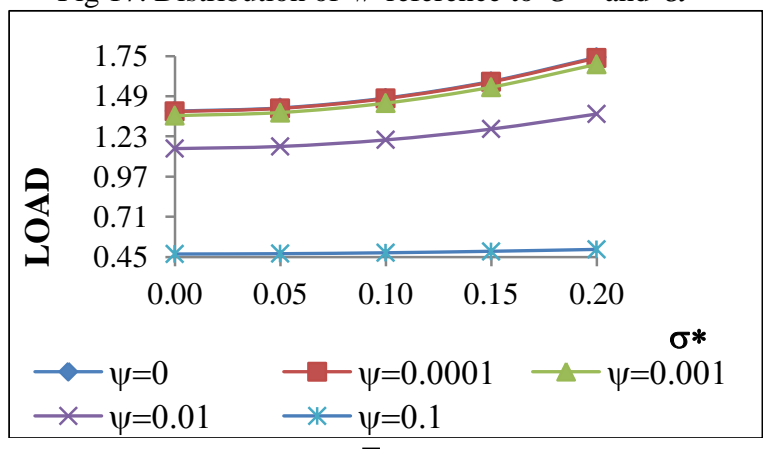

Fig-18. Distribution of $\bar{w}$ reference to $\sigma^{*}$ and $\psi$

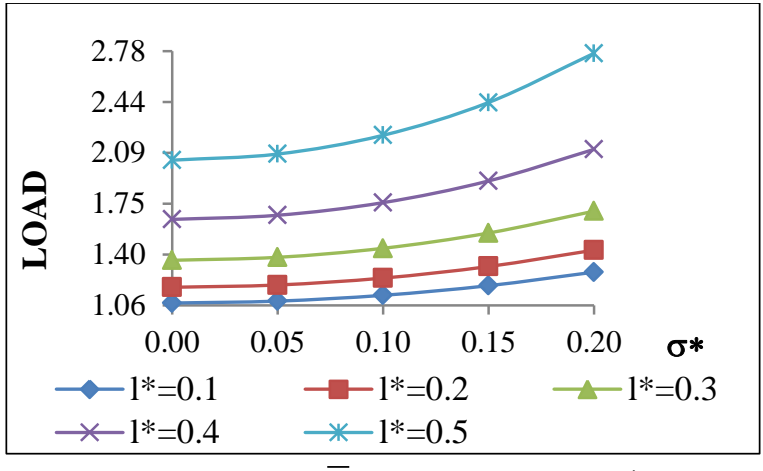

The impact of $\varepsilon^{*}$ on $\bar{w}$ with regards to $l^{*}$ and $\psi$ can be described from Fig 20-21. Negatively increases the value of $\varepsilon^{*}$ increases the value of $\bar{w}$ while the $\bar{w}$ is decreasing as $\varepsilon^{*}$ growing positively.

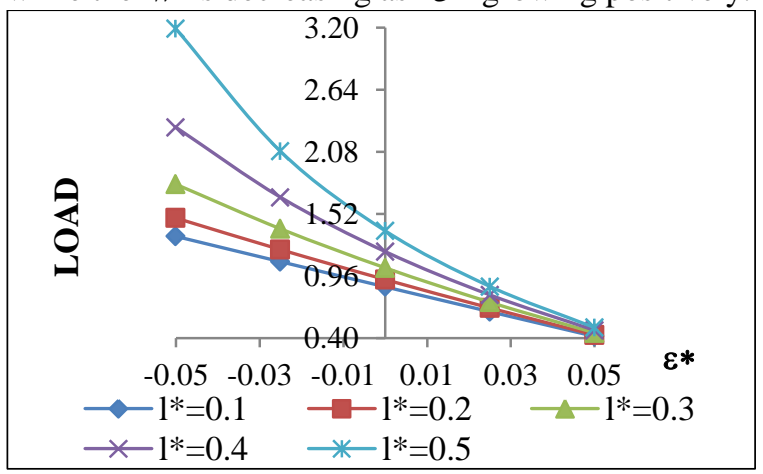

Fig-20. Distribution of $\bar{w}$ reference to $\varepsilon^{*}$ and $l^{*}$

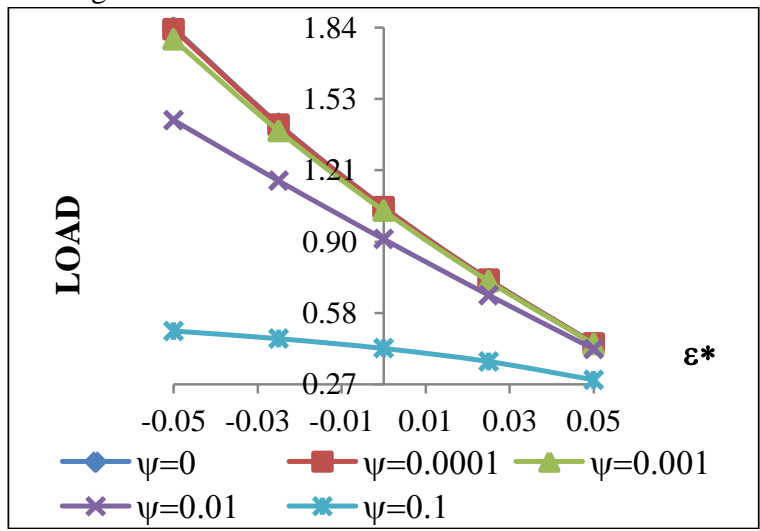

Fig-21. Distribution of $\bar{w}$ reference to $\varepsilon^{*}$ and $\psi$

Table 1 and 2 characterizes the comparison of current study with analysis of Biradar (2012) for smooth bearing and Y.D.vashi et al.(2018) for transverse roughness. The relative increase in $\bar{w}\left(R_{\bar{w}}\right)$ is calculated in Table 1 and Table 2. It is notice from Table 1 that comparative percentage of growth in $\bar{w}$ associate with transverse roughness is closely around $46 \%$ when $H^{*}=2.1$ and $l^{*}=0.5$.It is also notice that comparative percentage of growth in $\bar{w}$ associate with Biradar(2012) for smooth bearing is around $70 \%$ when $H^{*}=2.1$ and $l^{*}=0.5$. 
International Journal of Research in Advent Technology, Vol.7, No.2, February 2019

E-ISSN: 2321-9637

\section{Available online at www.ijrat.org}

Fig-19. Distribution of $\bar{w}$ reference to $\sigma^{*}$ and $l^{*}$

Table.1 Distribution of $\bar{w}$ and $R_{-}$for different values of $H^{*}$ and $l^{*}$

\begin{tabular}{|c|c|c|c|c|c|c|}
\hline \multicolumn{7}{|c|}{$\mu^{*}=0.15, K=0.65, \sigma^{*}=0.05, \alpha^{*}=-0.025, \varepsilon^{*}=-0.025, \psi=0.001$} \\
\hline$H^{*}$ & $l^{*}$ & $\begin{array}{l}\bar{w} \text { of } \\
\text { Biradar(2012)for } \\
\text { Smooth bearing }\end{array}$ & $\begin{array}{l}\bar{w} \text { Y.D. } \\
\text { Vashi et al. } \\
(2018) \text { for } \\
\text { transverse } \\
\text { roughness }\end{array}$ & $\begin{array}{l}\bar{w} \text { of current } \\
\text { study for } \\
\text { longitudinal } \\
\text { roughness }\end{array}$ & $\begin{array}{l}R_{w} \\
\text { compare to } \\
\text { Transverse } \\
\text { roughness }\end{array}$ & $\begin{array}{l}R_{w}^{-} \\
\text {compare to } \\
\text { Biradar(2012) } \\
\text { for smooth } \\
\text { bearing }\end{array}$ \\
\hline \multirow{3}{*}{1.3} & 0.1 & 0.87258597 & 0.97004352 & 1.20662921 & 24.39 & 38.28 \\
\hline & 0.3 & 1.03716394 & 1.16738226 & 1.52197513 & 30.38 & 46.74 \\
\hline & 0.5 & 1.35860961 & 1.57293262 & 2.25848835 & 43.58 & 66.24 \\
\hline \multirow{3}{*}{2.1} & 0.1 & 0.7753509 & 0.86591309 & 1.08878456 & 25.74 & 40.42 \\
\hline & 0.3 & 0.92594391 & 1.0472427 & 1.38492109 & 32.24 & 49.57 \\
\hline & 0.5 & 1.22027141 & 1.42098761 & 2.08307866 & 46.59 & 70.71 \\
\hline \multirow{3}{*}{2.9} & 0.1 & 0.75680271 & 0.84656878 & 1.06869999 & 26.24 & 41.21 \\
\hline & 0.3 & 0.90624152 & 1.02664939 & 1.36353046 & 32.81 & 50.46 \\
\hline & 0.5 & 1.19835981 & 1.39798933 & 2.05917969 & 47.30 & 71.83 \\
\hline
\end{tabular}

From Table 2 It is notice that that comparative percentage of growth in $\bar{w}$ associate with transverse roughness is closely around $47 \%$ when $K=0.45$ and

$l^{*}=0.5$.It is also notice that comparative percentage of growth in $\bar{w}$ associate with Biradar (2012) is around $70 \%$ when $K=0.65$ and $l^{*}=0.5$.

Table 2. Variation of $\bar{w}$ and $R_{-}$for different values of $K$ and $l^{*}$

\begin{tabular}{|c|c|c|c|c|c|c|}
\hline \multicolumn{7}{|c|}{$\mu^{*}=0.15, H^{*}=2.10, \sigma^{*}=0.05, \alpha^{*}=-0.025, \varepsilon^{*}=-0.025, \psi=0.001$} \\
\hline$K$ & $l^{*}$ & $\begin{array}{l}\bar{w} \text { of } \\
\text { Biradar(2012)for } \\
\text { Smooth bearing }\end{array}$ & $\begin{array}{l}\bar{w} \text { Y.D. } \\
\text { Vashi et al. } \\
(2018) \text { for } \\
\text { transverse } \\
\text { roughness }\end{array}$ & $\begin{array}{l}\bar{w} \text { of current } \\
\text { study for } \\
\text { longitudinal } \\
\text { roughnes }\end{array}$ & $\begin{array}{l}R_{\bar{w}} \\
\text { compare to } \\
\text { Transverse } \\
\text { roughness }\end{array}$ & $\begin{array}{l}R_{w}^{-} \\
\text {compare to } \\
\text { Biradar(2012) } \\
\text { for smooth } \\
\text { bearing }\end{array}$ \\
\hline \multirow{3}{*}{0.45} & 0.1 & 0.94399940 & 1.03545889 & 1.31390527 & 26.89 & 39.18 \\
\hline & 0.3 & 1.13135356 & 1.26122332 & 1.68346368 & 33.48 & 48.80 \\
\hline & 0.5 & 1.49758370 & 1.72675214 & 2.55537177 & 47.99 & 70.63 \\
\hline \multirow{3}{*}{0.65} & 0.1 & 0.77535090 & 0.86591309 & 1.08878456 & 25.74 & 40.42 \\
\hline & 0.3 & 0.92594391 & 1.04724270 & 1.38492109 & 32.24 & 49.57 \\
\hline & 0.5 & 1.22027141 & 1.42098761 & 2.08307866 & 46.59 & 70.71 \\
\hline \multirow{3}{*}{0.85} & 0.1 & 0.46332820 & 0.53947821 & 0.65952852 & 22.25 & 42.35 \\
\hline & 0.3 & 0.54590807 & 0.63859735 & 0.81982459 & 28.38 & 50.18 \\
\hline & 0.5 & 0.70720589 & 0.84252954 & 1.19652002 & 42.02 & 69.19 \\
\hline
\end{tabular}




\section{Available online at www.ijrat.org}

\section{CONCLUSION}

The squeeze film based ferrofluid lubrication for longitudinally rough porous parallel stepped plates with couple stress effect is studied. On the basis of the graphical and tabular results following conclusions are made.

The influence of ferrofluid lubrication combine with couple stress effect enhances the load bearing capacity compared to conventional lubricant based bearing system.

The load increases almost $70 \%$ greater compared to the conventional lubricant based bearing system.

From industry point of view, the longitudinal roughness turns out to be more favorable as compared to transverse roughness.

The contrary effect of porosity and roughness can be compensated with the proper selection of step location with magnetization parameter and couple stress effect.

\section{REFERENCES}

[1] Stokes, V. (1966). Couple stresses in fluids. The Physics of fluids 9, 1709-1715.

[2] Siddangouda, A. (2015). Squeezing film Characteristics for Micropolar fluid between porous parallel Stepped plates. Tribology in industry 37(1), 97-106.

[3] Biradar, K. (2012). Sqeeze film lubrication between parallel stepped plates with couple stress fluids. International journal of Statistika and Mathematica 3(2), 65-69.

[4] Biradar, T. (2013). Squeeze film lubrication between porous parallel stepped plates with couple stress fluids. Tribology online 8(5), 278284.

[5] Lin, J. (1998). Squeeze film characteristics of finite journal bearings: couple stress fluid model. Tribology International 31 (4), 201-207.

[6] Ramanaiah, G. and P. Sarkar (1978). Squeeze films and thrust bearings lubricated by fluids with couple stress. Wear 48(2), 309-316.

[7] Naduvinamani N., Siddangouda A. (2009) Squeeze film lubrication between Circular Stepped Plates of Couple Stress fluids. Journal of Brazilian society of Mechanical science and Engineering 31(1), 21-26.

[8] Lin, J., C. Hung and R. Lu (2006). Averaged inertia principle for non-Newtonian squeeze films in wide parallel plates couple stress fluid model. Journal of Marine Science and Technology 14(4), 218-224.

[9] Shah R.C. (2003). "Ferrofluid lubrication in step bearing with two steps", Industrial Lubrication and Tribology 55(6), 265-267.

[10] Christensen, H. and K. Tonder (1969a). Tribology of rough surface: Stochastic models of hydrodynamic lubrication. SINTEF, Report No.10/69-18.

[11] Christensen, H. and K. Tonder (1969b). Tribology of rough surfaces: parametric study and comparison of lubrication models. SINTEF, Report No.22/69-18.

[12] Christensen, H. and K. Tonder (1970). The hydrodynamic lubrication of rough bearing surfaces of finite width. ASME-ASLE Lubrication conference, Cincinnati, Ohio. Paper no. 70-Lub-7.

[13] Andharia P.I., G. Deheri (2011). Effect of Longitudinal Roughness on Magnetic Fluid based Squeeze Film between Truncated Conical Plates.FDMP 7(1), 111-124.

[14] Shimpi, M.E. G. Deheri (2014) Effect of slip velocity and bearing deformation on the performance of a truncated conical plates, Iranian Journal of Science and Technology Transactions of Mechanical Engineering,38, 195-206.

[15] Patel J.R., G. Deheri (2016) The effect of Slip velocity on the ferrofluid based film in longitudinally rough conical plates, Journal of the Serbian Society for Computational Mechanics, 10 (2) ,18-29.

[16] Patel, J.R., Shimpi, M.E., Deheri G. M. (2017) Ferrofluid based squeeze film for a rough conical bearing with deformation effect, International conference on Research and invoations in Science, Engineering and Technology, Kalpa Publications in Computing 2, 119-129(2017).

[17] Kudenatti R.B., S. Patil, P. Dinesh, Vinay C. (2013) Numerical study of surface roughness and magnetic field between rough and porous rectangular plates, Mathematical problem in Engineering 2013, Article ID 915781, 8 pages.

[18] Neuringer, J., R. Rosensweig (1964). Magnetic fluids. Physics of fluids 7(12), 1927-1937.

[19] Vashi Y. D., Patel R. M., G. Deheri (2018) Ferrofluid based squeeze film lubrication between rough stepped plates with couple stress effect, Journal of Applied fluid Mechanics11(3), 597-612.

\section{NOMENCLATURE}

\begin{tabular}{|l|l|}
\hline$b$ & Width of the bearing \\
\hline$h_{1}$ & Maximum film thickness $(\mathrm{mm})$ \\
\hline$h_{2}$ & Minimum film thickness $(\mathrm{mm})$ \\
\hline$V$ & Normal velocity of bearing \\
& surface $(\mathrm{m} / \mathrm{s})$ \\
\hline$H$ & Thickness of the porous facing \\
\hline
\end{tabular}


International Journal of Research in Advent Technology, Vol.7, No.2, February 2019 E-ISSN: 2321-9637

Available online at www.ijrat.org

\begin{tabular}{|c|c|}
\hline$H^{*}$ & $\begin{array}{l}\text { Non dimensional mean film thickness } \\
\left(\frac{h_{1}}{h_{2}}\right)\end{array}$ \\
\hline$K L$ & Position of the step $(0<K<1)$ \\
\hline$l$ & Couple stress parameter $\left(\sqrt{\frac{\eta}{\mu}}\right)$ \\
\hline$l^{*}$ & $\begin{array}{l}\text { Non dimensional couple stress } \\
\text { parameter }\left(\frac{2 l}{h_{2}}\right)\end{array}$ \\
\hline$L$ & Length of the bearing \\
\hline$p_{1}$ & $\begin{array}{l}\text { Pressure in the fluid film region } \\
(0<x<K L)\left(\mathrm{N} / \mathrm{m}^{2}\right)\end{array}$ \\
\hline$p_{2}$ & $\begin{array}{l}\text { Pressure in the fluid film region } \\
(K L<x<L)\left(\mathrm{N} / \mathrm{m}^{2}\right)\end{array}$ \\
\hline$w$ & Load carrying capacity $(\mathrm{N})$ \\
\hline $\bar{w}$ & Non dimensional load capacity \\
\hline$\alpha$ & Variance $(\mathrm{mm})$ \\
\hline$\alpha^{*}$ & Non dimensional variance $\left(\frac{\alpha}{h_{2}}\right)$ \\
\hline$\varepsilon$ & Skewness (mm) \\
\hline
\end{tabular}

\begin{tabular}{|c|c|}
\hline$\varepsilon^{*}$ & Non dimensional skewness $\left(\frac{\varepsilon}{h_{2}^{3}}\right)$ \\
\hline$\eta$ & couple stress constant of the lubricant \\
\hline$\mu$ & $\begin{array}{l}\text { Dynamic viscosity of lubricant } \\
\left(\mathrm{N} . \mathrm{S} / \mathrm{m}^{2}\right)\end{array}$ \\
\hline$\mu_{0}$ & Permeability of free space $\left(\mathrm{N} / \mathrm{A}^{2}\right)$ \\
\hline $\bar{\mu}$ & Magnetic susceptibility of particle \\
\hline$\mu^{*}$ & $\begin{array}{l}\text { Non dimensional magnetization } \\
\text { parameter }\left(-\frac{\mu_{0} \bar{\mu} A h_{2}^{3}}{\mu V}\right)\end{array}$ \\
\hline$\sigma$ & Standard deviation $(\mathrm{mm})$ \\
\hline$\sigma^{*}$ & $\begin{array}{l}\text { Non dimensional standard deviation } \\
\left(\frac{\sigma}{h_{2}}\right)\end{array}$ \\
\hline $\boldsymbol{\varphi P}$ & Permeability of the porous facing $\left(\mathrm{m}^{2}\right)$ \\
\hline$\psi$ & Porosity $\left(\frac{\varphi H}{h_{2}^{3}}\right)$ \\
\hline
\end{tabular}

